\title{
$\alpha$-admissible mappings and related fixed point theorems
}

\author{
Nawab Hussain ${ }^{1}$, Erdal Karapınar ${ }^{2}$, Peyman Salimi $^{3}$ and Farhana Akbar ${ }^{*}$
}

${ }^{\text {*Correspondence: }}$

ridaf75@yahoo.com

${ }^{4}$ Department of Mathematics,

GDCW, Bosan Road, Multan,

Pakistan

Full list of author information is

available at the end of the article

\begin{abstract}
In this paper, we prove the existence and uniqueness of a fixed point for certain $\alpha$-admissible contraction mappings. Our results generalize and extend some well-known results on the topic in the literature. We consider some examples to illustrate the usability of our results.
\end{abstract}

MSC: 46N40; 47H10; 54H25; 46T99

Keywords: $\alpha$-admissible mappings; contractive mappings; fixed point

\section{Introduction}

Fixed point theory is one of the outstanding subfields of nonlinear functional analysis. It has been used in the research areas of mathematics and nonlinear sciences (see, e.g., [1-8]). In 1922 Banach [10] proved that in a complete metric space every contraction has a unique fixed point. In the proof of this theorem, he not only showed the existence and uniqueness of a fixed point, but also provided a method (generally, iterative) for constructing the fixed point. This property of the Banach theorem differentiates it from other fixed point theorems. Therefore, the Banach fixed point theorem has attracted great attention of authors since then (see, e.g., [11-48]). On the other hand, the fixed point technique suggested by Banach attracted many researchers to solve various concrete problems.

\section{Main results}

In an attempt to generalize the Banach contraction principle, many researchers extended the following result in certain directions.

Theorem 1 (See, e.g., $[9,37,38])$ Let $(X, d)$ be a complete metric space and $f: X \rightarrow X$ be a mapping. Assume that there exists a function $\beta:[0, \infty) \rightarrow[0,1]$ such that, for any bounded sequence $\left\{t_{n}\right\}$ of positive reals, $\beta\left(t_{n}\right) \rightarrow 1$ implies $t_{n} \rightarrow 0$ and

$$
d(f x, f y) \leq \beta(d(x, y)) d(x, y)
$$

for all $x, y \in X$. Then $f$ has a unique fixed point.

Definition 2 (See, e.g., [40]) Let $f: X \rightarrow X$ and $\alpha: X \times X \rightarrow \mathbb{R}_{+}$. We say that $f$ is an $\alpha$ admissible mapping if

$$
\alpha(x, y) \geq 1 \quad \text { implies } \quad \alpha(f x, f y) \geq 1, \quad x, y \in X .
$$

๑ 2013 Hussain et al.; licensee Springer. This is an Open Access article distributed under the terms of the Creative Commons Attribution License (http://creativecommons.org/licenses/by/2.0), which permits unrestricted use, distribution, and reproduction in any medium, provided the original work is properly cited. 
Example $3(c f$. [40]) Let $X=\mathbb{R}$. Define $f: X \rightarrow X$ and $\alpha: X \times X \rightarrow[0, \infty)$ by

$$
f x=\left\{\begin{array}{ll}
\ln |x| & \text { if } x \neq 0, \\
3 & \text { otherwise }
\end{array} \quad \text { and } \quad \alpha(x, y)= \begin{cases}3 & \text { if } x \geq y \\
0 & \text { otherwise }\end{cases}\right.
$$

Then $f$ is $\alpha$-admissible.

Our first result is the following.

Theorem 4 Let $(X, d)$ be a complete metric space and $f: X \rightarrow X$ be an $\alpha$-admissible mapping. Assume that there exists a function $\beta:[0, \infty) \rightarrow[0,1]$ such that, for any bounded sequence $\left\{t_{n}\right\}$ of positive reals, $\beta\left(t_{n}\right) \rightarrow 1$ implies $t_{n} \rightarrow 0$ and

$$
(d(f x, f y)+\ell)^{\alpha(x, f x) \alpha(y, f y)} \leq \beta(d(x, y)) d(x, y)+\ell
$$

for all $x, y \in X$ where $\ell \geq 1$. Suppose that either

(a) $f$ is continuous, or

(b) if $\left\{x_{n}\right\}$ is a sequence in $X$ such that $x_{n} \rightarrow x, \alpha\left(x_{n}, x_{n+1}\right) \geq 1$ for all $n$, then $\alpha(x, f x) \geq 1$. If there exists $x_{0} \in X$ such that $\alpha\left(x_{0}, f x_{0}\right) \geq 1$, then $f$ has a fixed point.

Proof Let $x_{0} \in X$ such that $\alpha\left(x_{0}, f x_{0}\right) \geq 1$. Define a sequence $\left\{x_{n}\right\}$ in $X$ by $x_{n}=f^{n} x_{0}=f x_{n-1}$ for all $n \in \mathbb{N}$. If $x_{n+1}=x_{n}$ for some $n \in \mathbb{N}$, then $x=x_{n}$ is a fixed point for $f$ and the result is proved. Hence, we suppose that $x_{n+1} \neq x_{n}$ for all $n \in \mathbb{N}$. Since $f$ is an $\alpha$-admissible mapping and $\alpha\left(x_{0}, f x_{0}\right) \geq 1$, we deduce that $\alpha\left(x_{1}, x_{2}\right)=\alpha\left(f x_{0}, f^{2} x_{0}\right) \geq 1$. By continuing this process, we get $\alpha\left(x_{n}, f x_{n}\right) \geq 1$ for all $n \in \mathbb{N} \cup\{0\}$. By the inequality (2.1), we have

$$
\begin{aligned}
d\left(f x_{n-1}, f x_{n}\right)+\ell & \leq\left(d\left(f x_{n-1}, f x_{n}\right)+\ell\right)^{\alpha\left(x_{n-1}, f x_{n-1}\right) \alpha\left(x_{n}, f x_{n}\right)} \\
& \leq \beta\left(d\left(x_{n-1}, x_{n}\right)\right) d\left(x_{n-1}, x_{n}\right)+\ell
\end{aligned}
$$

then

$$
d\left(x_{n}, x_{n+1}\right) \leq \beta\left(d\left(x_{n-1}, x_{n}\right)\right) d\left(x_{n-1}, x_{n}\right),
$$

which implies $d\left(x_{n}, x_{n+1}\right) \leq d\left(x_{n-1}, x_{n}\right)$. It follows that the sequence $\left\{d\left(x_{n}, x_{n+1}\right)\right\}$ is decreasing. Thus, there exists $d \in \mathbb{R}_{+}$such that $\lim _{n \rightarrow \infty} d\left(x_{n}, x_{n+1}\right)=d$. We will prove that $d=0$. From (2.2) we have

$$
\frac{d\left(x_{n}, x_{n+1}\right)}{d\left(x_{n-1}, x_{n}\right)} \leq \beta\left(d\left(x_{n-1}, x_{n}\right)\right) \leq 1
$$

which implies $\lim _{n \rightarrow \infty} \beta\left(d\left(x_{n-1}, x_{n}\right)\right)=1$. Using the property of the function $\beta$, we conclude that

$$
\lim _{n \rightarrow \infty} d\left(x_{n}, x_{n+1}\right)=0
$$

Next, we will prove that $\left\{x_{n}\right\}$ is a Cauchy sequence. Suppose, to the contrary, that $\left\{x_{n}\right\}$ is not a Cauchy sequence. Then there is $\varepsilon>0$ and sequences $\{m(k)\}$ and $\{n(k)\}$ such that, 
for all positive integers $k$, we have

$$
n(k)>m(k)>k, \quad d\left(x_{n(k)}, x_{m(k)}\right) \geq \varepsilon \quad \text { and } \quad d\left(x_{n(k)}, x_{m(k)-1}\right)<\varepsilon .
$$

By the triangle inequality, we derive that

$$
\begin{aligned}
\varepsilon & \leq d\left(x_{n(k)}, x_{m(k)}\right) \leq d\left(x_{n(k)}, x_{m(k)-1}\right)+d\left(x_{m(k)-1}, x_{m(k)}\right) \\
& <\varepsilon+d\left(x_{m(k)-1}, x_{m(k)}\right)
\end{aligned}
$$

$k \in \mathbb{N}$. Taking the limit as $k \rightarrow+\infty$ in the above inequality and using (2.3), we get

$$
\lim _{k \rightarrow+\infty} d\left(x_{n(k)}, x_{m(k)}\right)=\varepsilon
$$

Again, by the triangle inequality, we find that

$$
d\left(x_{n(k)}, x_{m(k)}\right) \leq d\left(x_{m(k)}, x_{m(k)+1}\right)+d\left(x_{m(k)+1}, x_{n(k)+1}\right)+d\left(x_{n(k)+1}, x_{n(k)}\right)
$$

and

$$
d\left(x_{n(k)+1}, x_{m(k)+1}\right) \leq d\left(x_{m(k)}, x_{m(k)+1}\right)+d\left(x_{m(k)}, x_{n(k)}\right)+d\left(x_{n(k)+1}, x_{n(k)}\right) .
$$

Taking the limit as $k \rightarrow+\infty$, together with (2.3) and (2.4), we deduce that

$$
\lim _{k \rightarrow+\infty} d\left(x_{n(k)+1}, x_{m(k)+1}\right)=\varepsilon
$$

From (2.1), (2.4) and (2.5) we have

$$
\begin{aligned}
d\left(x_{n(k)+1}, x_{m(k)+1}\right)+\ell & \leq\left(d\left(x_{n(k)+1}, x_{m(k)+1}\right)+\ell\right)^{\left.\alpha\left(x_{n(k)}\right) f x_{n(k)}\right) \alpha\left(x_{m(k)}, f x_{m(k)}\right)} \\
& =\left(d\left(f x_{n(k)}, f x_{m(k)}\right)+\ell\right)^{\alpha\left(x_{n(k)}, f x_{n(k)}\right) \alpha\left(x_{m(k)}, f x_{m(k)}\right)} \\
& \leq \beta\left(d\left(x_{n(k)}, x_{m(k)}\right)\right) d\left(x_{n(k)}, x_{m(k)}\right)+\ell .
\end{aligned}
$$

Hence,

$$
\frac{d\left(x_{n(k)+1}, x_{m(k)+1}\right)}{d\left(x_{n(k)}, x_{m(k)}\right)} \leq \beta\left(d\left(x_{n(k)}, x_{m(k)}\right)\right) \leq 1 .
$$

Letting $k \rightarrow \infty$ in the above inequality, we get

$$
\lim _{n \rightarrow \infty} \beta\left(d\left(x_{n(k)}, x_{m(k)}\right)\right)=1
$$

That is, $\lim _{k \rightarrow \infty} d\left(x_{n(k)}, x_{m(k)}\right)=0<\varepsilon$, which is a contradiction. Hence $\left\{x_{n}\right\}$ is a Cauchy sequence. Since $X$ is complete, then there is $z \in X$ such that $x_{n} \rightarrow z$. First, we suppose that $f$ is continuous. Since $f$ is continuous, then we have

$$
f z=\lim _{n \rightarrow \infty} f x_{n}=\lim _{n \rightarrow \infty} x_{n+1}=z .
$$


So, $z$ is a fixed point of $f$. Next, we suppose that (b) holds. Then $\alpha(z, f z) \geq 1$. Now, by (2.1) we have

$$
\begin{aligned}
d\left(f z, x_{n+1}\right)+\ell & \leq\left(d\left(f z, f x_{n}\right)+\ell\right)^{\alpha(z, f z) \alpha\left(x_{n}, f x_{n}\right)} \\
& \leq \beta\left(d\left(z, x_{n}\right)\right) d\left(z, x_{n}\right)+\ell .
\end{aligned}
$$

That is, $d\left(f z, x_{n+1}\right) \leq \beta\left(d\left(z, x_{n}\right)\right) d\left(z, x_{n}\right)$, and so we get

$$
d(f z, z) \leq d\left(f z, x_{n+1}\right)+d\left(z, x_{n+1}\right) \leq \beta\left(d\left(z, x_{n}\right)\right) d\left(z, x_{n}\right)+d\left(z, x_{n+1}\right) .
$$

Letting $n \rightarrow \infty$ in the above inequality, we get $d(f z, z)=0$, that is, $z=f z$.

Example 5 Let $X=[0, \infty)$ be endowed with the usual metric $d(x, y)=|x-y|$ for all $x, y \in X$ and $f: X \rightarrow X$ be defined by

$$
f x= \begin{cases}\frac{x}{x+1} & \text { if } x \in[0,1] \\ 2 x & \text { if } x \in(1, \infty)\end{cases}
$$

Define also $\alpha: X \times X \rightarrow[0,+\infty)$ and $\beta:[0, \infty) \rightarrow[0,1]$ by

$$
\alpha(x, y)=\left\{\begin{array}{ll}
1 & \text { if } x, y \in[0,1], \\
0 & \text { otherwise }
\end{array} \quad \text { and } \quad \beta(t)=\frac{1}{1+t} .\right.
$$

We prove that Theorem 4 can be applied to $f$, but Theorem 1 cannot be applied to $f$.

Clearly, $(X, d)$ is a complete metric space. We show that $f$ is an $\alpha$-admissible mapping. Let $x, y \in X$, if $\alpha(x, y) \geq 1$, then $x, y \in[0,1]$. On the other hand, for all $x \in[0,1]$, we have $f x \leq 1$. It follows that $\alpha(f x, f y) \geq 1$. Thus the assertion holds. In reason of the above arguments, $\alpha(0, f 0) \geq 1$.

Now, if $\left\{x_{n}\right\}$ is a sequence in $X$ such that $\alpha\left(x_{n}, x_{n+1}\right) \geq 1$ for all $n \in \mathbb{N} \cup\{0\}$ and $x_{n} \rightarrow x$ as $n \rightarrow+\infty$, then $\left\{x_{n}\right\} \subset[0,1]$ and hence $x \in[0,1]$. This implies that $\alpha(x, f x) \geq 1$.

Let $x, y \in[0,1]$ and $y \geq x$. We get

$$
\begin{aligned}
(d(f x, f y)+\ell)^{\alpha(x, f x) \alpha(y, f y)} & =f y-f x+\ell=\frac{y}{y+1}-\frac{x}{x+1}+\ell \\
& =\frac{y-x}{(1+x)(1+y)}+\ell \\
& \leq \frac{y-x}{1+y-x}+\ell=\beta(d(x, y)) d(x, y)+\ell .
\end{aligned}
$$

Otherwise, $\alpha(x, f x) \alpha(y, f y)=0$ and so

$$
(d(f x, f y)+\ell)^{\alpha(x, f x) \alpha(y, f y)}=1 \leq \beta(d(x, y)) d(x, y)+\ell,
$$

then the condition of Theorem 4 holds. Hence, $f$ has a fixed point. Let $x=2$ and $y=3$. Then

$$
d(f 2, f 3)=2>\frac{1}{2}=\frac{1}{1+|2-3|}|2-3|=\beta(d(2,3)) d(2,3),
$$

that is, the contractive condition of Theorem 1 does not hold for this example. 
Theorem 6 Let $(X, d)$ be a complete metric space and $f: X \rightarrow X$ be an $\alpha$-admissible mapping. Assume that there exists a function $\beta:[0, \infty) \rightarrow[0,1]$ such that, for any bounded sequence $\left\{t_{n}\right\}$ of positive reals, $\beta\left(t_{n}\right) \rightarrow 1$ implies $t_{n} \rightarrow 0$ and

$$
(\alpha(x, f x) \alpha(y, f y)+1)^{d(f x, f y)} \leq 2^{\beta(d(x, y)) d(x, y)}
$$

for all $x, y \in X$. Suppose that either

(a) $f$ is continuous, or

(b) if $\left\{x_{n}\right\}$ is a sequence in $X$ such that $x_{n} \rightarrow x, \alpha\left(x_{n}, x_{n+1}\right) \geq 1$ for all $n$, then $\alpha(x, f x) \geq 1$. If there exists $x_{0} \in X$ such that $\alpha\left(x_{0}, f x_{0}\right) \geq 1$, then $f$ has a fixed point.

Proof Let $x_{0} \in X$ such that $\alpha\left(x_{0}, f x_{0}\right) \geq 1$. Define a sequence $\left\{x_{n}\right\}$ in $X$ by $x_{n}=f^{n} x_{0}=f x_{n-1}$ for all $n \in \mathbb{N}$. If $x_{n+1}=x_{n}$ for some $n \in \mathbb{N}$, then $x=x_{n}$ is a fixed point for $f$ and the result is proved. Hence, we suppose that $x_{n+1} \neq x_{n}$ for all $n \in \mathbb{N}$. As in Theorem 4 , we conclude that $\alpha\left(x_{n}, f x_{n}\right) \geq 1$ for all $n \in \mathbb{N} \cup\{0\}$. Due to (2.6) we have

$$
\begin{aligned}
2^{d\left(f x_{n-1}, f x_{n}\right)} & \leq\left(\alpha\left(x_{n-1}, f x_{n-1}\right) \alpha\left(x_{n}, f x_{n}\right)+1\right)^{d\left(f x_{n-1}, f x_{n}\right)} \\
& \leq 2^{\beta\left(d\left(x_{n-1}, x_{n}\right)\right) d\left(x_{n-1}, x_{n}\right)}
\end{aligned}
$$

which yields that

$$
d\left(x_{n}, x_{n+1}\right) \leq \beta\left(d\left(x_{n-1}, x_{n}\right)\right) d\left(x_{n-1}, x_{n}\right) .
$$

So, we conclude that $d\left(x_{n}, x_{n+1}\right) \leq d\left(x_{n-1}, x_{n}\right)$. It follows that the sequence $d_{n}:=d\left(x_{n}, x_{n+1}\right)$ is decreasing. Thus, there exists $d \in \mathbb{R}_{+}$such that $d_{n} \rightarrow d$ as $n \rightarrow \infty$. We claim that $d=0$. Suppose, to the contrary, that $d>0$. Considering (2.7), we obtain

$$
\frac{d\left(x_{n}, x_{n+1}\right)}{d\left(x_{n-1}, x_{n}\right)} \leq \beta\left(d\left(x_{n-1}, x_{n}\right)\right) \leq 1
$$

which implies $\lim _{n \rightarrow \infty} \beta\left(d\left(x_{n-1}, x_{n}\right)\right)=1$. Hence, $d=\lim _{n \rightarrow \infty} d_{n}=\lim _{n \rightarrow \infty} d\left(x_{n-1}, x_{n}\right)=0$, which is a contradiction. Hence, we derive that

$$
\lim _{n \rightarrow \infty} d\left(x_{n}, x_{n+1}\right)=0 .
$$

We prove that $\left\{x_{n}\right\}$ is a Cauchy sequence. Suppose, to the contrary, that $\left\{x_{n}\right\}$ is not a Cauchy sequence. Then there is $\varepsilon>0$ and sequences $\{m(k)\}$ and $\{n(k)\}$ such that, for all positive integers $k$,

$$
n(k)>m(k)>k, \quad d\left(x_{n(k)}, x_{m(k)}\right) \geq \varepsilon \quad \text { and } \quad d\left(x_{n(k)}, x_{m(k)-1}\right)<\varepsilon .
$$

Following the related lines in the proof of Theorem 4, we get

$$
\lim _{k \rightarrow+\infty} d\left(x_{n(k)}, x_{m(k)}\right)=\varepsilon
$$

and

$$
\lim _{k \rightarrow+\infty} d\left(x_{n(k)+1}, x_{m(k)+1}\right)=\varepsilon
$$


Now, from (2.6), (2.8) and (2.9), we have

$$
\begin{aligned}
2^{d\left(x_{n(k)+1}, x_{m(k)+1}\right)} & \leq\left(\alpha\left(x_{n(k)}, f x_{n(k)}\right) \alpha\left(x_{m(k)}, f x_{m(k)}\right)+1\right)^{d\left(x_{n(k)+1}, x_{m(k)+1}\right)} \\
& =\left(\alpha\left(x_{n(k)}, f x_{n(k)}\right) \alpha\left(x_{m(k)}, f x_{m(k)}\right)+1\right)^{\left.d\left(f x_{n(k)}\right) f x_{m(k)}\right)} \\
& \leq 2^{\beta\left(d\left(x_{n(k)}, x_{m(k)}\right)\right) d\left(x_{n(k)}, x_{m(k)}\right)}
\end{aligned}
$$

Hence,

$$
\frac{d\left(x_{n(k)+1}, x_{m(k)+1}\right)}{d\left(x_{n(k)}, x_{m(k)}\right)} \leq \beta\left(d\left(x_{n(k)}, x_{m(k)}\right)\right) \leq 1 .
$$

By taking limit as $k \rightarrow \infty$, we get

$$
\lim _{n \rightarrow \infty} \beta\left(d\left(x_{n(k)}, x_{m(k)}\right)\right)=1
$$

That is, $\lim _{k \rightarrow \infty} d\left(x_{n(k)}, x_{m(k)}\right)=0<\varepsilon$, which is a contradiction. Hence $\left\{x_{n}\right\}$ is a Cauchy sequence. Since $X$ is complete, then there is $z \in X$ such that $x_{n} \rightarrow z$. First of all, we suppose that $f$ is continuous. We obtain that

$$
f z=\lim _{n \rightarrow \infty} f x_{n}=\lim _{n \rightarrow \infty} x_{n+1}=z
$$

due to the continuity of $f$. Thus, we derived that $z$ is a fixed point of $f$.

Next, we suppose that (b) holds. Then, $\alpha(z, f z) \geq 1$. Now, by (2.6) we have

$$
\begin{aligned}
2^{d\left(f z, x_{n+1}\right)} & \leq\left(\alpha(z, f z) \alpha\left(x_{n}, f x_{n}\right)+1\right)^{d\left(f z, f x_{n}\right)} \\
& \leq 2^{\beta\left(d\left(z, x_{n}\right)\right) d\left(z, x_{n}\right)} .
\end{aligned}
$$

That is, $d\left(f z, x_{n+1}\right) \leq \beta\left(d\left(z, x_{n}\right)\right) d\left(z, x_{n}\right)$, and so we get

$$
d(f z, z) \leq d\left(f z, x_{n+1}\right)+d\left(z, x_{n+1}\right) \leq \beta\left(d\left(z, x_{n}\right)\right) d\left(z, x_{n}\right)+d\left(z, x_{n+1}\right) .
$$

By taking the limit as $n \rightarrow \infty$, we get $d(f z, z)=0$, i.e., $z=f z$.

Example 7 Let $X=[0, \infty)$ be endowed with the usual metric $d(x, y)=|x-y|$ for all $x, y \in X$ and $f: X \rightarrow X$ be defined by

$$
f x= \begin{cases}\frac{1}{8} x^{2} & \text { if } x \in[0,1] \\ \ln x & \text { if } x \in(1, \infty)\end{cases}
$$

Define also $\alpha: X \times X \rightarrow[0,+\infty)$ and $\beta:[0, \infty) \rightarrow[0,1]$ by

$$
\alpha(x, y)=\left\{\begin{array}{ll}
1 & \text { if } x, y \in[0,1], \\
0 & \text { otherwise }
\end{array} \text { and } \quad \beta(t)=\frac{1}{4} .\right.
$$

We prove that Theorem 6 can be applied to $f$, but Theorem 1 cannot be applied to $f$. 
By a similar method to that in the proof of Example 5, we can show that $f$ is an $\alpha$ admissible mapping and $\alpha\left(x_{n}, f x_{n}\right) \geq 1, x_{n} \rightarrow x$ as $n \rightarrow+\infty$ implies that $\alpha(x, f x) \geq 1$. Clearly, $\alpha(0, f 0) \geq 1$.

Let $x, y \in[0,1]$. Then

$$
\begin{aligned}
(\alpha(x, f x) \alpha(y, f y)+1)^{d(f x, f y)} & =2^{|f x-f y|}=2^{\frac{1}{8}|x-y||x+y|} \\
& \leq 2^{\frac{1}{4}|x-y|}=2^{\beta(d(x, y)) d(x, y)} .
\end{aligned}
$$

Otherwise, $\alpha(x, f x) \alpha(y, f y)=0$, and so

$$
\begin{aligned}
(\alpha(x, f x) \alpha(y, f y)+1)^{d(f x, f y)} & \leq(\alpha(x, f x) \alpha(y, f y)+1)^{d(f x, f y)} \\
& =1^{d(f x, f y)}=2^{0} \leq 2^{\beta(d(x, y)) d(x, y)},
\end{aligned}
$$

then the contractive condition of Theorem 6 holds and $f$ has a fixed point. Let $x=2$ and $y=4$; then

$$
d(f 2, f 4)=\ln 2>\frac{1}{2}=\frac{1}{4}|2-4|=\beta(d(2,4)) d(2,4) .
$$

That is, the contractive condition of Theorem 1 does not hold for this example.

Theorem 8 Let $(X, d)$ be a complete metric space and $f: X \rightarrow X$ be an $\alpha$-admissible mapping. Assume that there exists a function $\beta:[0, \infty) \rightarrow[0,1]$ such that, for any bounded sequence $\left\{t_{n}\right\}$ of positive reals, $\beta\left(t_{n}\right) \rightarrow 1$ implies $_{t_{n}} \rightarrow 0$ and

$$
\alpha(x, f x) \alpha(y, f y) d(f x, f y) \leq \beta(d(x, y)) d(x, y)
$$

for all $x, y \in X$. Suppose that either

(a) $f$ is continuous, or

(b) if $\left\{x_{n}\right\}$ is a sequence in $X$ such that $x_{n} \rightarrow x, \alpha\left(x_{n}, x_{n+1}\right) \geq 1$ for all $n$, then $\alpha(x, f x) \geq 1$. If there exists $x_{0} \in X$ such that $\alpha\left(x_{0}, f x_{0}\right) \geq 1$, then $f$ has a fixed point.

Proof Let $x_{0} \in X$ such that $\alpha\left(x_{0}, f x_{0}\right) \geq 1$. Define a sequence $\left\{x_{n}\right\}$ in $X$ by $x_{n}=f^{n} x_{0}=f x_{n-1}$ for all $n \in \mathbb{N}$. If $x_{n+1}=x_{n}$ for some $n \in \mathbb{N}$, then $x=x_{n}$ is a fixed point for $f$ and the result is proved. Hence, we suppose that $x_{n+1} \neq x_{n}$ for all $n \in \mathbb{N}$. As in Theorem 4 , we conclude that $\alpha\left(x_{n}, f x_{n}\right) \geq 1$ for all $n \in \mathbb{N} \cup\{0\}$. Now, by (2.10) we have

$$
\alpha\left(x_{n-1}, f x_{n-1}\right) \alpha\left(x_{n}, f x_{n}\right) d\left(f x_{n-1}, f x_{n}\right) \leq \beta\left(d\left(x_{n-1}, x_{n}\right)\right) d\left(x_{n-1}, x_{n}\right),
$$

then

$$
d\left(x_{n}, x_{n+1}\right) \leq \beta\left(d\left(x_{n-1}, x_{n}\right)\right) d\left(x_{n-1}, x_{n}\right) .
$$

It yields that $d\left(x_{n}, x_{n+1}\right) \leq d\left(x_{n-1}, x_{n}\right)$. It follows that the sequence $\left\{d\left(x_{n}, x_{n+1}\right)\right\}$ is decreasing. Consequently, there exists $d \in \mathbb{R}_{+}$such that $d\left(x_{n}, x_{n+1}\right) \rightarrow d$ as $n \rightarrow \infty$. Regarding (2.11), we observe that

$$
\frac{d\left(x_{n}, x_{n+1}\right)}{d\left(x_{n-1}, x_{n}\right)} \leq \beta\left(d\left(x_{n-1}, x_{n}\right)\right) \leq 1
$$


Thus, we find that $\lim _{n \rightarrow \infty} \beta\left(d\left(x_{n-1}, x_{n}\right)\right)=1$ by the property of the function $\beta$. Hence,

$$
\lim _{n \rightarrow \infty} d\left(x_{n}, x_{n+1}\right)=0 .
$$

Next, we will show that the sequence $\left\{x_{n}\right\}$ is Cauchy. Suppose, to the contrary, that $\left\{x_{n}\right\}$ is not a Cauchy sequence. Then there is $\varepsilon>0$ and sequences $\{m(k)\}$ and $\{n(k)\}$ such that, for all positive integers $k$,

$$
n(k)>m(k)>k, \quad d\left(x_{n(k)}, x_{m(k)}\right) \geq \varepsilon \quad \text { and } \quad d\left(x_{n(k)}, x_{m(k)-1}\right)<\varepsilon .
$$

Again, by following the lines of the proof of Theorem 4, we derive that

$$
\lim _{k \rightarrow+\infty} d\left(x_{n(k)}, x_{m(k)}\right)=\varepsilon
$$

and

$$
\lim _{k \rightarrow+\infty} d\left(x_{n(k)+1}, x_{m(k)+1}\right)=\varepsilon
$$

Combining (2.10), (2.12) and (2.13), we have

$$
\begin{aligned}
d\left(x_{n(k)+1}, x_{m(k)+1}\right) & \leq \alpha\left(x_{n(k)}, f x_{n(k)}\right) \alpha\left(x_{m(k)}, f x_{m(k)}\right) d\left(x_{n(k)+1}, x_{m(k)+1}\right) \\
& =\alpha\left(x_{n(k)}, f x_{n(k)}\right) \alpha\left(x_{m(k)}, f x_{m(k)}\right) d\left(f x_{n(k)}, f x_{m(k)}\right) \\
& \leq \beta\left(d\left(x_{n(k)}, x_{m(k)}\right)\right) d\left(x_{n(k)}, x_{m(k)}\right) .
\end{aligned}
$$

Hence,

$$
\frac{d\left(x_{n(k)+1}, x_{m(k)+1}\right)}{d\left(x_{n(k)}, x_{m(k)}\right)} \leq \beta\left(d\left(x_{n(k)}, x_{m(k)}\right)\right) \leq 1 .
$$

By taking limit as $k \rightarrow \infty$, we get

$$
\lim _{n \rightarrow \infty} \beta\left(d\left(x_{n(k)}, x_{m(k)}\right)\right)=1
$$

That is, $\lim _{k \rightarrow \infty} d\left(x_{n(k)}, x_{m(k)}\right)=0$. Hence $\left\{x_{n}\right\}$ is a Cauchy sequence. Since $X$ is complete, then there is $z \in X$ such that $x_{n} \rightarrow z$.

First, suppose that $f$ is continuous. Since $f$ is continuous, then we have

$$
f z=\lim _{n \rightarrow \infty} f x_{n}=\lim _{n \rightarrow \infty} x_{n+1}=z .
$$

So, $z$ is a fixed point of $f$.

We suppose that (b) holds. Then $\alpha(z, f z) \geq 1$. Now, by (2.10) we have

$$
\begin{aligned}
d\left(f z, x_{n+1}\right) & \leq \alpha(z, f z) \alpha\left(x_{n}, f x_{n}\right) d\left(f z, f x_{n}\right) \\
& \leq \beta\left(d\left(z, x_{n}\right)\right) d\left(z, x_{n}\right) .
\end{aligned}
$$


That is, $d\left(f z, x_{n+1}\right) \leq \beta\left(d\left(z, x_{n}\right)\right) d\left(z, x_{n}\right)$, and so we get

$$
d(f z, z) \leq d\left(f z, x_{n+1}\right)+d\left(z, x_{n+1}\right) \leq \beta\left(d\left(z, x_{n}\right)\right) d\left(z, x_{n}\right)+d\left(z, x_{n+1}\right) .
$$

Letting $n \rightarrow \infty$ in the above inequality, we get $d(f z, z)=0$, i.e., $z=f z$.

Example 9 Let $X=[0, \infty)$ be endowed with the usual metric $d(x, y)=|x-y|$ for all $x, y \in X$ and $f: X \rightarrow X$ be defined by

$$
f x= \begin{cases}\frac{1}{4}\left(1-x^{2}\right) & \text { if } x \in[0,1] \\ 3 x & \text { if } x \in(1, \infty) .\end{cases}
$$

Define also $\alpha: X \times X \rightarrow[0,+\infty)$ and $\beta:[0, \infty) \rightarrow[0,1]$ by

$$
\alpha(x, y)=\left\{\begin{array}{ll}
1 & \text { if } x, y \in[0,1], \\
0 & \text { otherwise }
\end{array} \text { and } \quad \beta(t)=\frac{1}{2} .\right.
$$

We prove that Theorem 8 can be applied to $f$ (here, a fixed point is $u=\sqrt{5}-2$ ), but Theorem 1 cannot be applied to $f$.

By a similar method to that in the proof of Example 5, we can show that $f$ is an $\alpha$ admissible mapping and $\alpha\left(x_{n}, f x_{n}\right) \geq 1, x_{n} \rightarrow x$ as $n \rightarrow+\infty$ implies that $\alpha(x, f x) \geq 1$. Clearly, $\alpha(0, f 0) \geq 1$.

Let $x, y \in[0,1]$. Then

$$
\alpha(x, f x) \alpha(y, f y) d(f x, f y)=|f x-f y|=\frac{1}{4}|x-y||x+y| \leq \frac{1}{2}|x-y|=\beta(d(x, y)) d(x, y) .
$$

Otherwise, $\alpha(x, f x) \alpha(y, f y)=0$, and so

$$
\alpha(x, f x) \alpha(y, f y) d(f x, f y)=0 \leq \beta(d(x, y)) d(x, y),
$$

then the conditions of Theorem 8 hold and $f$ has a fixed point. Let $x=3$ and $y=4$; then

$$
d(f 3, f 4)=3>\frac{1}{2}=\frac{1}{2}|3-4|=\beta(d(3,4)) d(3,4) .
$$

That is, the contractive condition of Theorem 1 does not hold for this example.

Theorem 10 Assume that all the hypotheses of Theorems 4, 6 and 8 hold. Adding the following condition:

(c) if $x=f x$ then $\alpha(x, f x) \geq 1$,

we obtain the uniqueness of the fixed point of $f$.

Proof Suppose that $z$ and $z^{*}$ are two fixed points of $f$ such that $z \neq z^{*}$. Then $\alpha(z, f z) \geq 1$ and $\alpha\left(z^{*}, f z^{*}\right) \geq 1$.

For Theorem 4 we have

$$
d\left(f z, f z^{\prime \prime}\right)+\ell \leq\left(d\left(f z, f z^{\prime \prime}\right)+\ell\right)^{\alpha(z, f z) \alpha\left(z^{\prime \prime}, f z^{\prime \prime}\right)} \leq \beta\left(d\left(z, z^{\prime \prime}\right)\right) d\left(z, z^{\prime \prime}\right)+\ell .
$$


For Theorem 6 we have

$$
(2)^{d\left(f z, f z^{*}\right)} \leq\left(\alpha(z, f z) \alpha\left(z^{*}, f z^{*}\right)+1\right)^{d\left(f z, f z^{\prime \prime}\right)} \leq(2)^{\beta\left(d\left(z, z^{*}\right)\right) d\left(z, z^{*}\right)} .
$$

For Theorem 8 we have

$$
d\left(f z, f z^{*}\right) \leq \alpha(z, f z) \alpha\left(z^{*}, f z^{*}\right) d\left(f z, f z^{*}\right) \leq \beta\left(d\left(z, z^{*}\right)\right) d\left(z, z^{*}\right)
$$

Hence, all the three inequalities separately imply that $\beta\left(d\left(z, z^{*}\right)\right)=1$. Thus $d\left(z, z^{*}\right)=0$, i.e., $z=z^{*}$ as required.

Remark 11 By utilizing the technique of Samet et al. [40], we can obtain corresponding coupled fixed point results from our Theorems 4, 6 and 8 .

\section{Competing interests}

The authors declare that they have no competing interests.

\section{Authors' contributions}

All authors contributed equally and significantly in writing this article. All authors read and approved the final manuscript.

\section{Author details}

'Department of Mathematics, King Abdulaziz University, P.O. Box 80203, Jeddah, 21589, Saudi Arabia. ${ }^{2}$ Department of Mathematics, Atilim University, Incek, Ankara 06836, Turkey. ${ }^{3}$ Department of Mathematics, Astara Branch, Islamic Azad University, Astara, Iran. ${ }^{4}$ Department of Mathematics, GDCW, Bosan Road, Multan, Pakistan.

\section{Acknowledgements}

This research was funded by the Deanship of Scientific Research (DSR), King Abdulaziz University, Jeddah. The first author acknowledges with thanks DSR, KAU for financial support. The 3rd author is thankful for support of Astara Branch, Islamic Azad University, during this research.

Received: 25 November 2012 Accepted: 26 February 2013 Published: 19 March 2013

\section{References}

1. Akbar, F, Khan, AR: Common fixed point and approximation results for noncommuting maps on locally convex spaces. Fixed Point Theory Appl. 2009, Article ID 207503 (2009)

2. Border, KC: Fixed Point Theorems with Applications to Economics and Game Theory. Cambridge University Press, Cambridge (1985)

3. Ok, EA: Real Analysis with Economic Applications. Princeton University Press, Princeton (2007)

4. Lai, X, Zhang, Y: Fixed point and asymptotic analysis of cellular neural networks. J. Appl. Math. 2012, Article ID 689845 (2012)

5. Kramosil, O, Michalek, J: Fuzzy metric and statistical metric spaces. Kybernetika 11, 326-334 (1975)

6. Menger, K: Statistical metrics. Proc. Natl. Acad. Sci. USA 28, 535-537 (1942)

7. Waszkiewicz, P: Partial metrisability of continuous posets. Math. Struct. Comput. Sci. 16(2), 359-372 (2006)

8. Dricia, Z, McRaeb, FA, Devi, JV: Fixed-point theorems in partially ordered metric spaces for operators with PPF dependence. Nonlinear Anal. 67, 641-647 (2007)

9. Amini-Harandi, A, Emami, H: A fixed point theorem for contraction type maps in partially ordered metric spaces and application to ordinary differential equations. Nonlinear Anal. 72, 2238-2242 (2010)

10. Banach, S: Sur les opérations dans les ensembles abstraits et leur application aux equations itegrales. Fundam. Math. 3, 133-181 (1922)

11. Hussain, $\mathrm{N}$, Berinde, $\mathrm{V}$, Shafqat, $\mathrm{N}$ : Common fixed point and approximation results for generalized $\phi$-contractions. Fixed Point Theory 10, 111-124 (2009)

12. Berinde, $\mathrm{V}$ : Common fixed points of noncommuting almost contractions in cone metric spaces. Math. Commun. 15(1), 229-241 (2010)

13. Berinde, $\mathrm{V}$ : Approximating common fixed points of noncommuting almost contractions in metric spaces. Fixed Point Theory 11(2), 179-188 (2010)

14. Berinde, $\vee$ : Common fixed points of noncommuting discontinuous weakly contractive mappings in cone metric spaces. Taiwan. J. Math. 14(5), 1763-1776 (2010)

15. Ciric, LB: A generalization of Banach principle. Proc. Am. Math. Soc. 45, 727-730 (1974)

16. Ćirić, L, Hussain, N, Cakic, N: Common fixed points for Ciric type $f$-weak contraction with applications. Publ. Math. (Debr) 76(1-2), 31-49 (2010)

17. Ćirić, L, Abbas, M, Saadati, R, Hussain, N: Common fixed points of almost generalized contractive mappings in ordered metric spaces. Appl. Math. Comput. 217, 5784-5789 (2011)

18. Edelstein, M: On fixed and periodic points under contractive mappings. J. Lond. Math. Soc. 37, 74-79 (1962) 
19. Hussain, N, Khamsi, MA, Latif, A: Banach operator pairs and common fixed points in hyperconvex metric spaces. Nonlinear Anal. 74, 5956-5961 (2011)

20. Hussain, N, Pathak, HK: Subweakly biased pairs and Jungck contractions with applications. Numer. Funct. Anal. Optim. 32(10), 1067-1082 (2011)

21. Hussain, N, Khamsi, MA: On asymptotic pointwise contractions in metric spaces. Nonlinear Anal. 71, 4423-4429 (2009)

22. Hussain, N, Cho, YJ: Weak contractions, common fixed points and invariant approximations. J. Inequal. Appl. 2009, Article ID 390634 (2009)

23. Hussain, N, Jungck, G: Common fixed point and invariant approximation results for noncommuting generalized $(f, g)$-nonexpansive maps. J. Math. Anal. Appl. 321, 851-861 (2006)

24. Kannan, R: Some results on fixed points. Bull. Calcutta Math. Soc. 60, 71-76 (1968)

25. Karapınar, E: Weak $\phi$-contraction on partial metric spaces. J. Comput. Anal. Appl. 14(2), 206-210 (2012)

26. Karapınar, E: Best proximity points of cyclic mappings. Appl. Math. Lett. 25(11), 1761-1766 (2012)

27. Karapınar, E, Erhan, IM: Fixed point theorems for operators on partial metric spaces. Appl. Math. Lett. 24, 1900-1904 (2011)

28. Karapınar, E: Generalizations of Caristi Kirk's theorem on partial metric spaces. Fixed Point Theory Appl. 2011, 4 (2011) doi:10.1186/1687-1812-2011-4

29. Karapınar, E, Yuksel, U: Some common fixed point theorems in partial metric spaces. J. Appl. Math. 2011, Article ID $263621(2011)$

30. Karapınar, E: A note on common fixed point theorems in partial metric spaces. Miskolc Math. Notes, 12(2), 185-191 (2011)

31. Karapınar, E: Generalizations of Caristi Kirk's theorem on partial metric spaces. Fixed Point Theory Appl. 2011, 4 (2011)

32. Aydi, H, Karapinar, E, Shatanawi, W: Tripled common fixed point results for generalized contractions in ordered generalized metric spaces. Fixed Point Theory Appl. 2012, 101 (2012)

33. Aydi, H, Karapinar, E, Erhan, I: Coupled coincidence point and coupled fixed point theorems via generalized Meir-Keeler type contractions. Abstr. Appl. Anal. 2012, Article ID 781563 (2012)

34. Karapinar, E, Yuce, IS: Fixed point theory for cyclic generalized weak $\phi$-contraction on partial metric spaces. Abstr. Appl. Anal. 2012, Article ID 491542 (2012)

35. Aydi, H, Vetro, C, Karapinar, E: Meir-Keeler type contractions for tripled fixed points. Acta Math. Sci. 32(6), 2119-2130 (2012)

36. Suzuki, T: A generalized Banach contraction principle that characterizes metric completeness. Proc. Am. Math. Soc. $136,1861-1869$ (2008)

37. Harjani, J, Sadarangani, K: Fixed point theorems for weakly contractive mappings in partially ordered sets. Nonlinear Anal. 71, 3403-3410 (2009)

38. Jachymski, J: Equivalent conditions for generalized contractions on (ordered) metric spaces. Nonlinear Anal. 74 768-774 (2011)

39. Karapinar, E, Samet, B: Generalized $(\alpha-\psi)$ contractive type mappings and related fixed point theorems with applications. Abstr. Appl. Anal. 2012, Article ID 793486 (2012)

40. Samet, B, Vetro, C, Vetro, P: Fixed point theorem for $\alpha-\psi$ contractive type mappings. Nonlinear Anal. 75, $2154-2165$ (2012)

41. Sintunavarat, $W$, Kumam, $P$ : Weak condition for generalized multi-valued $(f, \alpha, \beta)$-weak contraction mappings. Appl. Math. Lett. 24, 460-465 (2011)

42. Sintunavarat, W, Kumam, P: Gregus type fixed points for a tangential multi-valued mappings satisfying contractive conditions of integral type. J. Inequal. Appl. 2011, 3 (2011)

43. Sintunavarat, W, Cho, YJ, Kumam, P: Common fixed point theorems for c-distance in ordered cone metric spaces. Comput. Math. Appl. 62, 1969-1978 (2011)

44. Sintunavarat, W, Kumam, P: Common fixed point theorems for generalized $J H$-operator classes and invariant approximations. J. Inequal. Appl. 2011, 67 (2011)

45. Aydi, H, Vetro, C, Sintunavarat, W, Kumam, P: Coincidence and fixed points for contractions and cyclical contractions in partial metric spaces. Fixed Point Theory Appl. 2012, 124 (2012)

46. Nashine, HK, Sintunavarat, W, Kumam, P: Cyclic generalized contractions and fixed point results with applications to an integral equation. Fixed Point Theory Appl. 2012, 217 (2012)

47. Sintunavarat, W, Kumam, P: Generalized common fixed point theorems in complex valued metric spaces and applications. J. Inequal. Appl. 2012, 84 (2012)

48. Sintunavarat, W, Kim, JK, Kumam, P: Fixed point theorems for a generalized almost $(\phi, \varphi)$-contraction with respect to S in ordered metric spaces. J. Inequal. Appl. 2012, 263 (2012) 